\title{
One Instructor Teaching Multiple Graduate-Level Online Sections: Are There Differences?
}

\author{
Alma Mintu-Wimsatt, Ph.D. (Corresponding Author) \\ Department of Marketing \& Management, Texas A \& M University - Commerce \\ 42 Anderson Road, Neshanic Station, NJ 08853, USA
}

Tel: 1-214-534-1494_E-mail: alma_wimsatt@tamu-commerce.edu

Received: August 16, 2011 Accepted: September 12, 2011 Published: October 12, 2011

doi:10.5296/ije.v3i2.886ＵRL: http://dx.doi.org/10.5296/ije.v3i2.886

\begin{abstract}
Having the same instructor teach multiple graduate-level sections of a Marketing Management course using the same online teaching pedagogy assumes some level of consistency in the instruction. As a result, one would expect that student performance would generally be the same for both sections. However, anecdotal evidence from colleagues and personal experience seem to suggest otherwise. To empirically investigate if differences actually exist, this research compares the performance of online MBA students enrolled in two concurrent sections of a Marketing Management course. When comparing two sections of the said course, findings showed that Section \#1 students had significantly higher grades than Section \#2 students. The author found that the level of classroom participation and midterm grades were significantly different between the two sections. Based on these results, the author presents probable causes for such differences.
\end{abstract}

Keywords: Grade comparison, Multiple sections, Marketing class, Graduate MBA level, Motivation 


\section{Introduction}

For accreditation (i.e., comply with work load requirements) and efficiency (i.e., reduce faculty course preparation) purposes, university administrators are inclined to assign faculty members to teach multiple sections of the same course. From an administrative point of view, this is an effective way of increasing faculty class loads since teaching multiple sections reduces online course preparation time (Sammons \& Ruth, 2007). It also presupposes that students will receive consistent teaching pedagogy leading to better academic outcomes. And, because of this presumed level of consistency, the common practice of using one grading distribution for all sections is justified.

But, have you ever heard a colleague complain that one of his/her classes seems to be "better" than the other? Or perhaps, you may have made a comment that you "prefer" students in one section compared to the other since they tend to be more engaged. This is a common occurrence in a face-to-face classroom setting - perhaps because of the [F2F] student-teacher interaction or when dealing with undergraduate students whose motivation levels vary significantly.

Intuitively, the aforementioned scenarios ought to be alleviated when the same instructor is teaching multiple sections of online graduate courses. The online nature of courses removes the extraneous effects of the face-to-face student-teacher interaction and dynamics. Additionally, teaching multiple sections of the same course allows for more consistency in the teaching pedagogy. Moreover, graduate-level students are generally more motivated compared to their undergraduate counterparts. As a result, it would be reasonable to expect that student performance should be comparable across sections and that one grading distribution is warranted.

Despite almost of decade-long of teaching online graduate-level courses, this author has repeatedly found that discrepancies often existed between multiple sections. Invariably, one section would appear to do better than the other even when taught by the same instructor and following the same curriculum. So a compelling question is raised: Are these differences statistically significant? And, if significant differences do exist-why? More importantly, does this mean that pedagogical changes need to be made in order to give students in multiple sections an equal chance of performing well?

This author sought to examine the extant literature dealing with comparisons of multiple sections taught by the same instructor and using the online delivery method. Surprisingly, very little empirical research is available on the area. Even when the literature search was extended to include traditional face-to-face setting, empirical research on the area was unavailable. Instead, this author found a plethora of studies comparing student performance in traditional vs. technology-mediated (Gerlich \& Sollosy, 2011) or online (Beck, 2010) learning.

Herein lies the driving force behind this research. Because there is very little research in the area comparing performance outcomes in multiple sections taught by one instructor, there is a need to fill this gap in the literature with some empirical validation. Therefore, this study 
explores if the differences between sections are statistically significant? And if so, what causes these differences?

\section{Hypothesis Development}

In the past, much of the debate regarding student performance emanated from comparing students enrolled in face-to-face vs. online courses. Recent studies have shown that delivery method does not significantly impact students' learning (Beck, 2010). Interestingly, this remains consistent from the conclusions made almost two decades ago. Wetzel, Radtke \& Stern's (1994) review of the extant literature comparing student performance in distance education and conventional classroom setting found little significant differences between the two modes of pedagogical instruction. Findings such as Wetzel's et. al (1994) reinforced Russell’s (1992) “no significant difference” syndrome.

Now that online learning has been established as an effective means of delivery, its adoption has grown exponentially (Capra, 2011). Likewise, students have found themselves becoming more comfortable with technology-mediated learning environments. The ease and convenience of taking online courses have proven to be appealing to a vast number of students, especially among graduate students. Consequently, most colleges and universities in the United States offer some form of online learning - ranging from completely web-based degree programs to web-enhanced (or hybrid) courses (Capra, 2011).

Along with the growing demand for online courses, it has also become a common practice for instructors to teach multiple sections of the same course. This eases an instructor's workload since online teaching preparation general requires more time \& effort (Sammons \& Ruth, 2007). Additionally, having the same instructor teaching multiple sections presupposes some level of consistency. As a result, one would expect that student performance would be relatively comparable especially among graduate students. While it can be argued that student performance differences are inherent regardless of the instructor, these differences are often minimized when dealing with graduate students. In general, graduate students are usually high achievers and tend to be more self-motivated. Therefore, student performance tends to be more comparable across sections.

Because of this author's repeated experience of student outcome disparities when teaching multiple online sections of the same course, she embarked on a study comparing the performance of the students enrolled in two online concurrent sections of a graduate Marketing Management course. Unfortunately, the extant literature does not have other studies that could serve as a platform for this author's exploration.

It is noteworthy to mention that the online delivery method is a critical point for comparative purposes since it rules out the extraneous factors emanating from face-to-face student-teacher interaction/dynamics as well as the time of day and day of week the courses are offered. Likewise, comparing graduate-level students (i.e., MBA students) is important since they tend to be a more homogenous group of active and driven learners. Therefore, one would expect that the performance outcomes from MBA students in Section \#1 and Section \#2 would tend to be relatively similar. 
Hypothesis: No significant differences will be observed in the grade outcomes of graduate-level students enrolled in two concurrent online sections (Section \#1 vs. Section \#2) taught by the same instructor.

\section{Background Information}

\subsection{Sample}

The current study involves MBA students enrolled in an AACSB accredited regional state university. The university campus is located approximately 60 miles from a major US metropolitan city but this particular course and its two sections used a completely web-based delivery method.

Two concurrent online sections of the graduate Marketing Management course were utilized in this study. Sections 1 and 2 were offered during the same semester and observed identical weekly schedules. Both sections followed the same syllabus as well. Section \#1 had 32 enrolled students while Section \#2 had 30 enrolled students. These MBA students often enroll in the Marketing Management course during the first year of their graduate program. Majority of the students are in the 25-35 age group and have worked for at least one year.

\subsection{Marketing Management Course}

The graduate Marketing Management course is one of the core courses in the MBA curriculum offered every semester. Multiple online sections are typically offered every semester. The same professor taught the two relevant sections in this study. This professor is a seasoned instructor of 20-plus years and has taught graduate-level Marketing Management online for the past ten years. Therefore, teaching style, technology familiarity and course content as other potential extraneous factors have been minimized.

Students' grades were evaluated based on four equally-weighted components (100 points/component): weekly discussion/participation; case submissions; mid-term and final examinations. Therefore, a total of 400 points can be earned by each student. Students were required to join bulletin board-type discussions on a weekly basis based on a specific topic indicated in their syllabus. The asynchronous discussion forum lasted for 3-cycle days (Sunday to Tuesday). Four case written analysis were required -2 prior to the midterm and 2 after. The midterm exam covered chapters during the first half of the semester. The final exam covered the latter half - it was not comprehensive exam. The exams comprised of 50 application-type multiple choice questions.

\section{Results}

To determine if there is significant difference between the total [or summative] grade outcomes in Section \#1 vs. Section \#2, an analysis of variance was conducted (ANOVA). We found that Section \#1's grade outcomes (Grade: 340.5) were marginally better than Section 2's (Grade: 328.9). The F-statistic was 3.679 significant at $\mathrm{p}<.10$. 


\section{Macrothink}

To further, explore these grade differences, we conducted post-hoc ANOVAs, looking into the differences based on the various grade components: midterm score, final exam score, participation/discussion grade, and case score. The reported ANOVAs were as follows:

Table 1. ANOVAs of the Grade Components

\begin{tabular}{|c|c|c|c|}
\hline Grade Components & Mean & F-statistic & Prob \\
\hline $\begin{array}{l}\text { Midterm score } \\
\text { Section \#1 }\end{array}$ & 76.1 & 2.791 & $.10 * *$ \\
\hline Section \#2 & 71.1 & & \\
\hline $\begin{array}{l}\text { Final exam score } \\
\text { Section \#1 }\end{array}$ & 79.6 & 1.771 & .19 \\
\hline Section \#2 & 75.4 & & \\
\hline $\begin{array}{l}\text { Participation } \\
\text { Section \#1 }\end{array}$ & 97.1 & 3.925 & $.05^{*}$ \\
\hline Section \#2 & 95.1 & & \\
\hline $\begin{array}{l}\text { Case scores } \\
\text { Section \#1 }\end{array}$ & 87.6 & .076 & .78 \\
\hline Section \#2 & 87.3 & & \\
\hline
\end{tabular}

As reported in Table 1 above, midterm score was marginally higher (at $\mathrm{p}<.10$ ) for Section \#1. Participation/discussion was also much better for Section \#1 (at $\mathrm{p}<.05$ ). No significant differences were found between final exam and case grades.

\section{Discussion \& Conclusion}

In general, Marketing Management is considered a core course for most MBA Programs. It is not uncommon that business schools offer multiple sections of this course both online and face-to-face. In examining the findings for two concurrent online sections, the results presented above shows that despite the instructor's efforts to achieve pedagogical and assessment consistencies, differences between these online sections can still arise. The differences found in this study are quite interesting since most extraneous factors prevalent when comparing two multiple sections have been minimized.

Since differences were found in the final summative grades between the students in Section \#1 vs. Section \#2, further analysis on what led to these differences was warranted. Therefore, each of the grade components was compared. 
Based on the findings in this study, no significant differences were found in the case grades of Sections \#1 and \#2. This is can be expected due to the fairly straight-forward nature of how case studies are generally conducted in the MBA level (i.e., usually following the Harvard-style of analysis). No differences were noted in the final exam grade as well. Perhaps, this is because MBA students were able to make adjustments in preparing for the final exam as a result of their experience in taking the mid-term.

The differences found between midterm and participation grades are noteworthy. In particular, Section \#1 students seemed to perform better than Section \#2 in these two grade components. As a result, this skewed the final letter grade results, whereby Section \#1 ended up getting higher final [letter] grades than Section \#2 students.

So, why do some online sections perform better than others? Specifically, why is Section \#1 better [in some regard] than Section \#2 in terms of their participation and mid-term exam performance? It is this author's opinion that these differences can be explained by the nature of how the mid-term and the participation grade components were evaluated as well as due to the students' motivation levels.

The mid-term exam was the first exam these MBA students took in the course. Without much precedence on the nature of exam, some students will be more prepared than others. The same is true during the discussions. Some students will be more engaged and active than others (see Xie, Durrington \& Yen, 2011). Therefore, the extent by which a student participates in the bulletin-board discussion format as well as his/her level of preparation for the mid-term could be driven by the student's personal motivation level (Xie, Durrington \& Yen, 2011).

Based on this study's findings, it appears that the more motivated students typically end up in Section \#1. Perhaps, this is because in most university enrollment/registration systems, those who register early typically end up in or are "rolled into" Section \#1. These "early" registrants are probably more concerned in planning their MBA degree and course sequencing. In other words, they tend to be more engaged and responsible. Hence, it is highly possible that Section \#1 is comprised of students who are generally more engaged in their MBA courses, including Marketing Management. These students, therefore, are generally more motivated and driven to perform better in class.

If this is indeed the case, this situation mandates that educators look at how instructors decide on their grade distribution. The typical practice for an instructor teaching multiple sections is to treat each section the same - adhering to the same grading and distribution system. But in doing so, are the students' grades biased against those enrolled in Section \#2? Should grade distribution be different for each section? To answer these questions, further investigation and comparisons in the area are warranted.

\section{References}

Beck, V. (2010). Comparing online and face-to-face teaching and learning. Journal of Excellence in College Teaching, 21, 95-108 


\section{Macrothink}

International Journal of Education

ISSN 1948-5476

2011, Vol. 3, No. 2: E5

Capra, T. (2011). Online education: Promise and problems. Journal of Online Learning \& Teaching, 7, 288-293.

Gerlich, R., \& M. Sollosy (2011). Comparing outcomes between a traditional F2F course and a blended ITV course, Journal of Case Studies in Education, 1. [Online] Available: http://www.aabri.com/jcse.html

Russell, T. (1992). Television's indelible impact on distance education: What we should have learned from comparative research. Research in Distance Education, 4, 2-4.

Sammons, R, \& S. Ruth (2007). The invisible professor and the future of virtual faculty. International Journal for Instructional Technology and Distance Learning, 4, 3-17.

Wetzel, C., P. Radtke, \& H. Stern (1994). Instructional effectiveness of video media. Hillsdale, NJ: Erlbaum.

Xie, K., V. Durrington \& L. Yen (2011). Relationship between students' motivation and their participation in asynchronous online discussions. Journal of Online Learning \& Teaching, 7, 17-29.

\section{Copyright Disclaimer}

Copyright reserved by the author.

This article is an open-access article distributed under the terms and conditions of the Creative Commons Attribution license (http://creativecommons.org/licenses/by/3.0/). 